\title{
Computer-based calculation of atmospheric pollutant emissions by automobile transport at controlled crossings
}

\author{
Gennady Denisov ${ }^{1}$, Vladimir Zelikov ${ }^{1,{ }^{*}}$, Elena Tarasova ${ }^{1}$, and Vladimir Klyavin ${ }^{2}$ \\ ${ }^{1}$ Voronezh State University of Forestry and Technologies Named after G.F. Morozov, 8 Timiryazeva \\ Str., Voronezh, 394087, Russia \\ ${ }^{2}$ Lipetsk State Technical University, 398600 Lipetsk, Russia
}

\begin{abstract}
The paper uses pollutant emissions calculation methods in accordance with GOST (All-Union State Standard) in combination with the method of mathematical statistics, which makes it possible to determine the amount of emissions from automobile transport, which is in line at a red traffic light in the area of a controlled intersection. The methods allow calculating such environmental indicators as the mass of pollutant emissions, the concentration of pollutants and the Air Pollution Index. The authenticity of this technique is confirmed by testing the hypothesis on the Pearson Law of distribution of pollutants. Based on the combined methodology, the software has been developed with the purpose to monitor atmospheric air pollution. This approach will make it possible to qualitatively assess the level of atmospheric air pollution and take timely measures in the event of dangerous environmental conditions.
\end{abstract}

\section{Introduction}

The state economic development accompanied by the rapid growth of energetics, transport, production sector, and, as a consequence, by the consumption of a large amount of natural resources, results in a great number of harmful emissions and industrial waste. In a certain way, all this affects the natural environment and the population's health condition. The negative impact of industry and energy consumption on the environment and public health has become not only a kind of local and regional troubles, but also of global ones [1].

The motor transport complex (MTC), which includes rolling stock, motor transport enterprises, garages, parking lots, service stations, gas stations, road facilities, etc., directly participates in environmental pollution. Every year, the global automotive fleet consumes approximately 2.2 billion tons of fuel and emits about 750 million tons of harmful pollutants into the atmosphere, including 450 million tons of carbon oxides (CO), 180 million tons of hydrocarbons $(\mathrm{CH}), 80$ million tons of nitrogen oxides (NOX), 18 million tons of soot and 0.7 million tons of lead. The total share of air pollution in developed countries reaches $47 \ldots 55 \%$. In addition, about 520 million tons of industrial waste are annually generated by MTC enterprises [2].

\footnotetext{
${ }^{1}$ Corresponding author: zelikov-vrn@mail.ru
} 
The Russian Federation is no exception. The volume of automobile transport (AT) in atmospheric pollution reached $42 \%$, including $52 \ldots 62 \%$ in cities, $86 \ldots 92 \%$ in megalopolises, and the share of industrial waste by MTC enterprises exceeded 22 million tons per year.

Obviously, all countries and especially developed ones with a significant automotive fleet should take urgent measures to reduce the harmful effects of the MTC and increase its environmental safety [3, 4].

In this regard, to control the level of quality of atmospheric air and the state of the environment, it is necessary to carry out environmental monitoring.

Ecological monitoring (monitoring of the natural environment) is a set of measures aimed at the research of the state of the environment, including its components, processes, phenomena occurring in them, changes in the state of the environment as a whole [3, 4].

Monitoring of atmospheric air is a system of the atmospheric air state quality level control, including the amount and composition of impurities and harmful substances contained in it, which influence the air in an anthropogenic way from stationary and mobile sources. Monitoring is carried out by sampling air and rainwater by permanent and mobile stations of the Federal Service for Hydrometeorology and Environmental Monitoring of Russia, Sanitary Epidemiological Surveillance and other units [3].

The problem of environmental pollution, as well as the negative impact on the health of the population, has become more and more urgent in course of time.

The basic solution to this problem is the improvement and development of environmental monitoring systems carried out on a modern organizational and technological basis.

The aim of the work is to determine the mass of pollutant emissions from automobile transport, to calculate the concentration of pollutants and the integrated Air Pollution Index (API).

To achieve this goal, it is necessary to solve the following tasks:

1. Determine the actual amount of automobile transport waiting at the red traffic light and calculate the masses of pollutant emissions, the concentration of pollutants and API.

2. Construct a normal distribution curve to test the hypothesis based on the Pearson Law of distribution.

3. Develop software for computer-based monitoring of atmospheric air pollution.

\section{Materials and Methods}

When conducting this research, GOST R 56162-2014 "Emissions of Pollutants into the Atmosphere. The Method for Calculating Emissions from Vehicles when Conducting Summary Calculations for Urban Settlements", Methods of mathematical statistics were used [5].

Methods of experimental research, information technology, mathematical modeling and programming, spatial analysis in the VBA (MS EXCEL) environment were applied $[6,7]$.

Controlled crossings were examined, the mass of emissions and the concentration of pollutants were determined.

Models, algorithms, methodologies, software and hardware, computer equipment, video surveillance and fixation cameras were used.

\section{Observation and Interpretation}

Voronezh is a developed city with almost a million inhabitants. The city's territory is divided into six municipal districts. In the right-bank part of the city, there are 
Kominternovsky, Tsentralny, Leninsky and Sovetsky districts, in the left-bank Zheleznodorozhny and Levoberezhny ones.

Large arterial streets, that sometimes do not meet the modern regulatory requirements of the transport infrastructure, pass through densely populated microdistricts of the city, and not in all areas they provide the necessary traffic capacity and, accordingly, safe protection of the population living next to the street, from exhaust gases and noise impact. The situation is getting worse every year due to a large increase in the number of personal vehicles and fixed-route taxi-buses, which flooded the city, in the truest sense of this word $[8,9,10]$.

The reason for the high level of atmospheric air pollution, in addition to the traffic congestion of the city's highways, is the lack of proper landscaping, the proximity of the residential area to the roadway, which does not meet modern urban planning regulatory requirements.

Air pollution in Voronezh occurs when pollutants are emitted by vehicles both at crossings and on the tracks (stages between traffic light objects) of the road network. The main share of emissions at crossings occurs when automobiles are in the queue on their way to a traffic light object (the largest amount of emissions from automobiles occurs when the engine is idling) [11]. On the tracks, emissions occur during the movement of automobiles (the minimum emission takes place at a vehicle speed of $60 \mathrm{~km} / \mathrm{h}$ ) [8]. If the congestion from the crossing covers the entire length of the track, then emissions are taken in the same quantity for this track as for the queue before the crossing.

To monitor the road network environmental situation in Voronezh, we used the methodology according to GOST R 56162-2014 "Emissions of Pollutants into the Atmosphere".

At the first stage, we calculated the masses of pollutant emissions in the area of the controlled crossing using the following formula [2]:

$$
M_{\Pi i}=\frac{P}{3600} \cdot \sum_{n-1}^{N_{L}} \sum_{k-1}^{N_{2 p}}\left(M_{\Pi i, k}^{\prime} \cdot G_{k, n}\right), \mathrm{g}
$$

where $\mathrm{P}$ is duration of the red (and yellow) traffic light, sec.;

$\mathrm{N}_{ц}$ is a number of cycles of a red traffic light action in a 60-minute period;

$\mathrm{N}_{\text {гр }}$ is a number of groups of automobiles;

$M_{\Pi i, k}^{\prime}$ is emission factor of the i-th pollutant by automobiles, g/min; of the k-th group in the "queue" at the red traffic light;

$\mathrm{G}_{\mathrm{k}, \mathrm{n}}$ is a number of automobiles of the k-th group, which are in the "queue" in the area of the crossing at the end of the $n$-th cycle of the prohibiting traffic light.

In total, 5 main types of pollutants were considered - $\mathrm{CO}, \mathrm{CH}, \mathrm{NO}_{2}, \mathrm{SO}_{2}, \mathrm{PM}$ (soot).

At the second stage of the study, the normal distribution curve was determined [5].

1. By the sample of volume $n=24$, all the numerical characteristics of a random variable were determined (where $\mathrm{X}$ is the total mass of emissions of five types of pollutants)

First, we found the number of intervals

$$
k=1+3,2 \cdot \lg (n)
$$

Since this value can only be an integer value, we rounded it to the nearest integer value.

Then we determined the length of the interval

$$
h=\left(x_{\max }-x_{\min }\right) / k
$$


Based on the initial data and calculation results, the completing took place.

Class boundaries were calculated

$$
\begin{aligned}
& \text { for the } 1^{\text {st }}-x_{\min } \ldots x_{\min }+h \\
& \text { for the } 2^{\text {nd }}-x_{\min }+h \ldots x_{\min }+2 \cdot h \\
& \ldots \\
& \text { for the } \mathrm{n} \text {-th }-x_{\min }+h(n-1) \ldots x_{\min }+n \cdot h
\end{aligned}
$$

Basic numerical characteristics are as follows

2). Sample mean

$$
\bar{x}_{s}=\frac{1}{n} \sum_{i=1}^{n} x_{i} \cdot n_{i} ;\left(\bar{x}_{B} \approx M(X)\right)
$$

3). Sample variance

$$
D_{B}=\frac{1}{n} \sum_{i=1}^{n} x_{i}^{2} \cdot n_{i}-\left(\bar{x}_{B}\right)^{2}
$$

4). Sample standard deviation

$$
\sigma_{B}=\sqrt{D_{B}}
$$

5). Corrected sample standard deviation

$$
S=\sqrt{\frac{n}{n-1} \cdot D_{\text {в }}} ;(S \approx \sigma(X))
$$

6). Coefficient of variation

$$
V=\frac{\sigma_{B}}{\bar{x}_{B}} \cdot 100 \%
$$

7). The normal distribution curve was plotted according to empirical data.

Since there was an assumption that the random variable $\mathrm{X}$, which characterized the pollutant emissions, was distributed normally, the equalizing frequencies were calculated in accordance with the following formula:

$$
n_{i}^{\prime}=\frac{n \cdot h}{S} \cdot \varphi\left(t_{i}\right)
$$

where $t_{i}=\frac{x_{i}-\bar{x}_{6}}{S}\left(x_{i}\right.$ is the middle of the $\mathrm{i}$-th partial interval);

$\varphi\left(t_{i}\right)$ is the value of the function found from the Table [5].

To make sure that the distribution of a random variable was normal, we used Pearson's criterion.

At the third stage of the study, the hypothesis about the Pearson's Law of distribution was tested.

The hypothesis about the assumed distribution law was tested according to the following algorithm.

1. We hypothesize $\mathrm{H}_{0}$ : a random variable is distributed according to the normal law.

2 . We calculate the equalizing frequencies $n_{i}^{\prime}$ according to the formula (10).

3) We find the observed value of the criterion $\chi_{\text {набл }}^{2}$. 


$$
\chi_{\text {набл }}^{2}=\sum_{i=1}^{k} \frac{\left(n_{i}-n_{i}^{\prime}\right)^{2}}{n_{i}^{\prime}}
$$

4) We determine the number of degrees of freedom

$$
m=k-1-r
$$

where $k$ is a number of partial sampling intervals; $r$ is a number of parameters of the assumed distribution.

For the normal law, the number of degrees of freedom is as follows:

$$
m=k-3
$$

Next, we find the critical value.

$$
\chi_{\kappa p}^{2}=\chi^{2}(\alpha ; m)
$$

where $\alpha$ is a predetermined significance level $(\alpha=0,05)$

We obtain $\chi_{k p}^{2}=\chi^{2}(0,05 ; 2)=5,99$

When $\chi_{\text {набл }}^{2}\left\langle\chi_{\kappa p}^{2}\right.$, the law of theoretical distribution does not contradict the experimental data, there is no reason to reject the hypothesis about the chosen law of distribution.

At the fourth stage of the study, the average daily concentration of pollutant emissions over the highway was determined using a Gaussian distribution model and the obtained values were compared with the norms, $\mathrm{g} / \mathrm{m}^{3}[1]$ :

$$
C_{i}=\frac{M_{\text {іссуточна }}}{1800 \cdot \sigma \cdot U \cdot 0,3 \cdot \sqrt{2 \cdot 3,14}}, \mathrm{~g} / \mathrm{m}^{3}
$$

where $\sigma$ is standard deviation of Gaussian dissemination over a highway, $\mathrm{m}$; $U$ is wind speed over a highway, $\mathrm{m} / \mathrm{sec}$; $\mathrm{h}$ is average height of the exhaust gas source (light motor vehicle exhaust), $\mathrm{m}(\mathrm{h}=0,3 \mathrm{~m})$.

At the fifth stage, the API was calculated based on the values of the average annual concentrations:

$$
\text { In }=\sum\left(\frac{x_{i}}{\Pi Д K_{i}}\right) \cdot C i
$$

where $\mathrm{x}_{\text {год } \mathrm{i}}$ is daily average concentration of the $\mathrm{i}$-th substance;

ПДК $\mathrm{i}_{\mathrm{i}}$ maximum permissible daily average concentration of the $\mathrm{i}$-th substance;

$\mathrm{C}_{\mathrm{i}}$ is coefficient allowing to reduce the degree of pollution by the $\mathrm{i}$-th pollutant to the degree of air pollution with sulfur dioxide.

API contamination levels are as follows:

$<5-$ low,

5-8 - increased,

8-13 - high

$>13$ - very high.

This method was used to develop the software (SW).

The software for monitoring the environmental situation on the street and road network of Voronezh basically uses the calculation method of GOST R 56162-2014 and the Law of normal distribution, which are implemented as follows [5].

The software is a VBA (MS EXCEL) environment [6, 7]. To start the software on the master form of the program, we press the start button $[12,13]$.

Then we open the window for additional parameters for entering the duration of the traffic light cycle at the crossing (Fig. 1). 
Then we open the data entry windows - choosing the time of day and night by the hour and the number of ATs in the queue at the red traffic light by the following groups:

- Light motor vehicles.

- Trucks with carrying capacity up to 2 tons inclusive.

- Trucks with a carrying capacity of $8 \ldots 14$ tons.

- Minibuses.

- Buses.

After entering the data in the morning, afternoon and evening hours, we open the window for determining the normal distribution curve of the mass of pollutant emissions and select the required parameters, after which the software automatically calculates them.

Then a data entry window appears for calculating the concentration of pollutant emissions. In this window, we select the radiation level by time of day and night, distance from the road from the drop-down list and enter the wind speed, then click on the following buttons - Calculating Concentration and Air API.

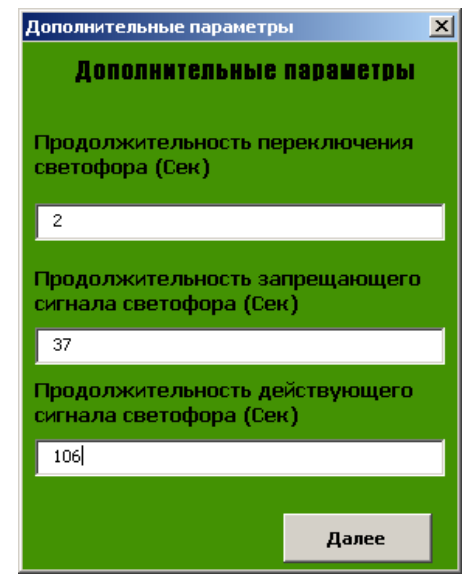

Fig. 1. Data Entry Window for the Duration of the Traffic Light Regulation Cycle

$\begin{array}{ll}\text { Text: } & \text { Additional Parameters } \\ & \text { Additional Parameters } \\ & \text { Traffic light switching duration (sec.) } \\ 2 & \\ & \text { Red traffic light duration (sec.) } \\ 37 & \text { Actuating traffic light duration (sec.) } \\ 106\end{array}$

In addition to displaying the concentration of pollutants and the complex index of API, the software compares the obtained values with the normative ones in accordance with GOST [4].

If the API values are exceeded, a button appears to recommend some measures to reduce the negative impact of automobile transport on the atmospheric air.

To clarify the situation, the software displays diagrams of pollutant emissions mass, concentrations and their comparison with standard values.

Also, each separate page of the program shows diagrams of the values obtained during the calculation:

- normal distribution curve;

- the traffic stream mix (in percentage);

- the composition of pollutants (percentage);

- mass of pollutant emissions in the morning; 
- mass of pollutant emissions during the daytime;

- mass of pollutant emissions in the evening;

- comparative mass of pollutant emissions per day;

- concentration of each of 5 pollutants and its comparison with the standard values;

- value of the integrated API and its comparison with the standard values.

The program also contains the background that allows you to get acquainted with the basic information on the software product, how it works and what formulas are used for calculations, the impact of the considered pollutants on public health and the environment.

To test the program, one of the busiest AT crossings in the Kominternovsky district of the City of Voronezh was examined.

As an observation object, we chose a section of the road network in the area of the regulated crossing of Antonova-Ovseenko Street and 45th Strelkovoy Divizii Street in the City of Voronezh, which is a one-level junction.

Using the method of time-keeping observations, we measured the number of three types of automobile transport (light motor vehicles, trucks, buses) queuing up at the red traffic light (field observations) in the morning from 8.00 a.m. to 12.00 p.m., in the afternoon from 12.00 p.m. to 4.00 p.m. and in the evening from 4.00 p.m. to 8.00 p.m. (We chose the hourly average values of the number of vehicles at the red traffic light.)

Then the time of the traffic light regulation cycle was measured (Table 1), and the data obtained were entered into the computer program.

Table 1. Traffic Light Duration

\begin{tabular}{|c|c|c|c|}
\hline $\mathrm{T}_{\mathrm{L}}$, sec. & $\mathrm{t}_{3}$, sec. & $\mathrm{t}_{\mathrm{kp}}, \mathrm{sec}$. & $\mathrm{t}_{\%}, \mathrm{sec}$. \\
\hline 142 & 112 & 28 & 2 \\
\hline
\end{tabular}

When calculating the environmental parameters at the intersection under study using software, the following results were obtained: $90 \%$ of the pollutant parameters ( 4 pollutants out of 5) exceed the standard values, respectively, the API is increased.

The distribution of pollutant emissions occurs according to the Law of normal distribution (Fig. 2).

We have $\chi_{k p}^{2}=\chi^{2}(0,05 ; 1)=4$.

When $\chi_{\text {набл }}^{2} \leq \chi_{\kappa p}^{2}$, the law of theoretical distribution does not contradict the experimental data, there is no reason to reject the hypothesis about the chosen law of distribution.

In our case, $0,87<3,81$, thus, there is no reason to reject the hypothesis about the chosen law of distribution.

The analysis of the obtained values allowed us to conclude that the experimental data are reliable, since:

1. The coefficient of variation $\mathrm{V}=15 \%$ (experimental data are considered to be reliable if the coefficient of variation does not exceed 20\%).

2. Fig. 2 shows a normal (theoretical) curve plotted for equalizing frequencies and a polygon of observed frequencies. Comparison of the graphs shows that the plotted theoretical curve satisfactorily reflects the observational data.

The closeness of theoretical and empirical frequencies testifies in favor of the assumption of the Law of normal distribution of the distribution of the pollutant emission mass.

The mass of emissions by time of day and night prevails during peak hours (in the morning from 8.00 a.m. to 9.00 a.m., in the afternoon from 12.00 p.m. to 1.00 p.m., in the evening from 6.00 p.m. to 7.00 p.m.). 
Since the level of the integrated air pollution index is increased, the following measures are envisaged to reduce the negative impact of AT:

1. Improvement of the AT and its technical conditions.

2. Increase in the pace and scope of works on urban planting and beautification.

The program displays them in a separate tab.

Normal Distribution Curves

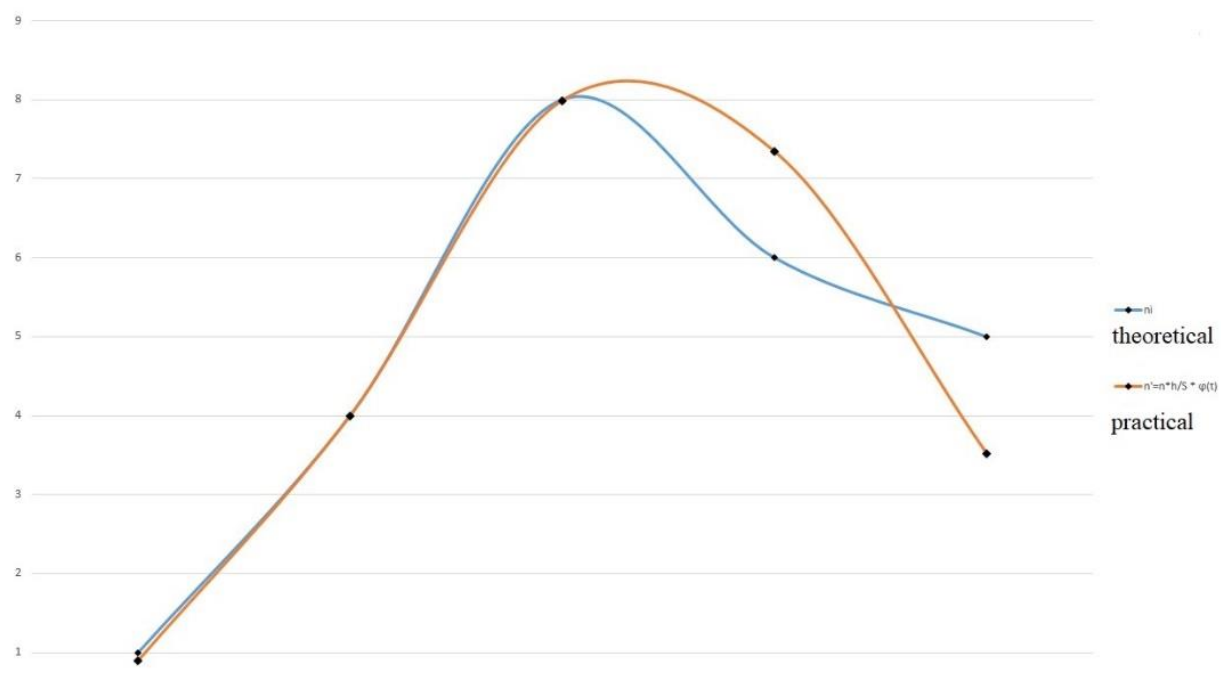

Fig. 2. Diagram of Theoretical and Experimental Normal Distribution Curves

\section{Conclusions}

The proposed work is devoted to detailed studies of the impact of automobile transport on the ecological state of large cities and megalopolises by the method of time-based observations of the traffic flow intensity with subsequent analytical calculation of atmospheric emissions of such pollutants as $\mathrm{CO}, \mathrm{CH}, \mathrm{NO} 2, \mathrm{SO} 2, \mathrm{PM}$ (soot).

The method for calculating emissions according to GOST R 56162-2014 using the Law of normal distribution is used. Computer software has been coded to make it possible to calculate the emissions of each of the specified pollutants, determine the API and give some recommendations concerning the improvement of environmental situation of the street and road networks of cities. The results of testing the program on a specific section of the main street in the City of Voronezh are presented.

The work has practical significance and it can be used to monitor the level of air pollution in the zone of controlled crossing and track. The results of the work can be used by the Department of Natural Resources and Ecology, as well as research institutes.

\section{References}

1. Sapronov I.V. Applied mathematics: laboratory practice. In 2 vol., Volume 1 [Text] / I.V. Sapronov, S.S. Venevitina, E.O. Utochkina // Ministry of Education and Science of the Russian Federation, VGLTU. - Voronezh, 2015. - 107 p.

2. Methods for conducting an inventory of pollutant emissions into the atmosphere for road transport enterprises (by calculation method). - M.: NIIAT Publ., 1998 - 44 p.

3. Bondarenko E.V. Road transport ecology: textbook / edited by A.A. Tsytsura. [Text] / E.V. Bondarenko, G.P. Dvornikov // Orenburg Publ.: GOU OSU, 2004 - 113 p. 
4. Erokhov V.I. Toxicity of modern cars. Methods and means of reducing harmful emissions into the atmosphere [Text] / V.I. Erokhov // Forum, Infra-M Publ., 2013 - 448 p.

5. Minko R.N. Transport and transport-technological systems of the country, its regions and cities, organization of production in transport [Text] / R.N. Minko // TransLit Publ., $2011-80 \mathrm{p}$.

6. Komolova N.V. VBA Programming in Excel 2016. Self-study guide / N.V. Komolova, E.S. Yakovleva. - SPb.: BHV-Petersburg Publ., 2017. - 432 p.

7. Kazansky A.A. Applied programming in Excel 2013: A handbook for applied bachelor's degree / A.A. Kazansky. - M.: Yurayt Publ., 2016. - 159 p.

8. Zelikov V.A. Development of software 'monitoring of atmospheric air pollution by road transport' [Text] / V.A. Zelikov, G.A. Denisov, E.V. Tarasova, E.A. Maklakova, N.S. Popova // Byulleten transportnoy informatsii [Bulletin of transport information]. 2019. No. 7 (289). pp. 3-7.

9. Novikov A.N. Optimization of bus fleet for city route servicing [Text] / A.N. Novikov, S.V. Eremin. // Mir transporta i tekhnologicheskikh mashin [The world of transport and technological machines]. - 2019. - No. 3 (66). - pp. 84-90.

10. Glagolev S.N. Reducing the ecological load of urban area by minimizing freight transport impact [Text] / S.N. Glagolev, A.G. Shevtsova, V.V. Vasilyeva // Mir transporta $i$ tekhnologicheskikh mashin [The world of transport and technological machines]. - 2020. - No. 3 (70). - pp. 97-106.

11. Vasilyeva V.V. Reducing CO emission levels from vehicles by determining rational modes of traffic lights operation at crossroads [Text] / V.V. Vasilyeva, A.A. Katunin, Yu. Charsky, D.O. Kozhin, D.E. Alekminsky // Mir transporta i tekhnologicheskikh mashin [The world of transport and technological machines]. - 2017. - No. 1 (56). - pp. 119-125.

12. Zelikov V.A. Improvement of methodology for calculating pollutant emissions by motor transport into the atmosphere [Text] / V.A. Zelikov G.A. Denisov, E.V. Shatalov, O. V. Fesikova, E.V. Tarasova // Transport. Transportnyye sooruzheniya. Ekologiya. [Transport. Transport facilities. Ecology]. - 2019. - No. 3. - pp. 31-40.

13. Denisov G.A. Program for calculating pollutant emissions by vehicles on a street-road network section of Voronezh [Text] / G.A. Denisov, E.V. Tarasova, A.M. Kulabukhov, I.V. Sherstyanikh., V.A. Zelikov // Registration certificate for computer program RU 2018660345, 22.08.2018. Application No. 2018617181 dated 10.07.2018. 